\title{
Review Article \\ The Effects of Tualang Honey on Bone Metabolism of Postmenopausal Women
}

\author{
Nadia Mohd Effendy, Norazlina Mohamed, Norliza Muhammad, \\ Isa Naina Mohamad, and Ahmad Nazrun Shuid \\ Department of Pharmacology, Faculty of Medicine, The National University of Malaysia, Kuala Lumpur Campus, \\ 50300 Kuala Lumpur, Malaysia
}

Correspondence should be addressed to Ahmad Nazrun Shuid, anazrun@yahoo.com

Received 7 June 2012; Revised 19 July 2012; Accepted 1 August 2012

Academic Editor: Srijit Das

Copyright (c) 2012 Nadia Mohd Effendy et al. This is an open access article distributed under the Creative Commons Attribution License, which permits unrestricted use, distribution, and reproduction in any medium, provided the original work is properly cited.

Osteoporosis which is characterized by low bone mass and microarchitectural deterioration with a consequent increase in bone fragility can be associated with various stimuli such as oxidative stress and inflammation. Postmenopausal women are more prone to osteoporosis due to reduction in estrogen which may further lead to elevation of oxidative stress and lipid accumulation which will promote osteoblasts apoptosis. Proinflammatory cytokines are elevated following estrogen deficiency. These cytokines are important determinants of osteoclasts differentiation and its bone resorption activity. The main treatment for postmenopausal osteoporosis is estrogen replacement therapy (ERT). Despite its effectiveness, ERT, however, can cause many adverse effects. Therefore, alternative treatment that is rich in antioxidant and can exert an anti-inflammatory effect can be given to replace the conventional ERT. Tualang honey is one of the best options available as it contains antioxidant as well as exerting anti-inflammatory effect which can act as a free radical scavenger, reducing the oxidative stress level as well as inhibiting proinflammatory cytokine. This will result in survival of osteoblasts, reduced osteoclastogenic activity, and consequently, reduce bone loss. Hence, Tualang honey can be used as an alternative treatment of postmenopausal osteoporosis with minimal side effects.

\section{Introduction}

Natural product has been used for medicinal purposes long before recorded history. Wide arrays of natural products used to treat a variety of ailments are also known as traditional medicine which is defined by the World Health Organization (WHO) as the sum total of the knowledge, skills, and practices based upon the theories, beliefs, and experiences indigenous to different cultures, whether explicable or not, used in the maintenance of health as well as in the prevention, diagnosis, improvement, or treatment of physical and mental illness [1]. Recently, it has been estimated that $80 \%$ of worldwide population rely on traditional medicines in order to meet their health care needs as an alternative to the conventional medicine [2]. Alternative medicine was first discovered as early as 5000 B.C in the Middle East, followed by the development of Ayurvedic, Chinese and Western medicine. Acceleration of the use of alternative treatment nowadays is due to rise in prevalence of chronic diseases, increasing costs of medical care and public concern on the rising adverse effects of conventional medicine.

Prevalence of chronic diseases is now increasing and contributed the most in medical care spending [3]. One of the serious diseases that is now becoming an important socioeconomic burden in many countries is osteoporosis. Osteoporosis is a systemic skeletal disease characterized by low bone mass and microarchitectural deterioration with a consequent increase in bone fragility with susceptibility to fracture [4]. According to National Osteoporosis Foundation, osteoporosis has become a major public health threat. The amount of medical care expenditure is rising tremendously due to increased elderly population as a result of increased longevity [5, 6]. Main factor causing osteoporosis are age-related decline in level of sex hormones 
(e.g., postmenopausal women), and secondary osteoporosis that can be due to diseases such as hypogonadism, hyperthyroidism, and gastrointestinal malabsorption syndromes [7]. Prolonged used of medications such as steroid prednisone, barbiturates, thyroxine and diabetic medications, excessive alcohol consumption, and smoking can contribute to bone loss as well [8-10]. Women are prone to tremendous estrogen reduction after menopause which will result in bone loss. This explains the fact that about $80 \%$ of the economic burden of osteoporosis has been attributed to its occurrence in women, especially in postmenopausal women [11]. Men, on the other hand, have a greater total bone mass than women, hence they are less likely to develop osteoporosis compared to women $[12,13]$.

To date, the main treatment of osteoporosis is hormone replacement therapy (HRT) and bisphosphonate. HRT, which contains estrogen has been shown to reduce hip fractures [14], wrist, vertebral and all nonvertebral fractures $[15,16]$. Although HRT is known to be very effective in increasing sex hormone level and improving bone mass, it can also produce many adverse effects, particularly breast cancer [17]. Estrogen can enhance the rate of cell proliferation in glandular tissue of breast and could potentially act both in initiation and promotion of breast cancer [18]. A study by Collaborative Group for Hormonal Factors in Breast Cancer has found out that women who had used HRT for longer than 5 years, the relative risk of breast cancer was 1.35 [19]. Other than that, prolonged use of HRT can also result in cardiac infarction, stroke, and pulmonary emboli [20]. Route of administration of HRT can be via oral, transdermal, patches, subcutaneous, and intramuscular injection. The most widely used method of administration is via intramuscular injection due to its rapid absorption. However, this method can be very painful. Other than HRT, bisphosphonates such as alendronate and risedronate are now widely used and have been approved to be used not only for treatment but also as prevention of osteoporosis. Alendronate and risedronate are able to inhibit osteoclastmediated bone resorption and reduce risk of fracture effectively. However, these treatments may contribute to adverse effects such as abdominal pain, joint and muscle pain, constipation [21], hypocalcemia, and osteonecrosis of the jaw bones [22].

Regardless the effectiveness of current available treatments of osteoporosis, alternative natural medicines are needed to treat this disease with minimal side effects. Honey is documented as one of the most ancient traditional remedies in history [23]. The first written reference to honey was a Sumerian tablet writing dating back to 2100-2000 B.C which mentions honey's use as a drug and ointment [24]. Since then it has become useful for both nutritional and medical purposes [25]. Honey has been of proven value in accelerating wound healing, as well as treating ulcers and skin infection [26, 27]. It has also shown to be an effective antioxidant and anti-inflammatory agent $[28,29]$. Honey consists of primarily sugars such as monosaccharides, disaccharides, oligosaccharides, and polysaccharides [30] as well as enzymes such as glucose oxidase, diastase, invertase, catalase, and peroxidase [31]. Other chemical contents of honey are organic acids, ascorbic acids, vitamins, amino acids, proteins, flavonoids and phenolic acids [32, 33]. These chemical constituents of honey made it beneficial in human health.

To date, there has been a resurgence in the use of honey in treating a wide array of diseases which are not only limited to wound healing. Malaysia is one of the countries in Asia that is well known for its varieties of honeys such as Tualang, Gelam, and Belimbing honey. Tualang honey is found on Asia's largest tree, Tualang tree or Koompassia excelsa. It has been used widely by the local community in treating wound, as beauty products, antiageing products, and health supplements [34]. Since the last few years, Tualang honey has been used widely by the researchers in order to discover its hidden potential values. The major components of Tualang honey are furfural derivatives such as 5-(hydroxymethyl)-furfural, furfural 2-furyl methyl ketone, 5-methyl furfural, and fatty acids such as palmitic acid, ethyl linoleate, and ethyl oleate [35]. Tualang honey is known for its antimicrobial, antiparasitic, antioxidant, and antiinflammatory effects which could be due to its chemical content that is high in antioxidative properties such as flavonoids and phenolic acids [36]. Recently, Tualang honey has been studied for its effect on bone density and a positive result was exhibited. This could make it a good potential as an alternative treatment to osteoporosis, replacing the conventional treatment. This paper focuses on the mechanisms of Tualang honey on bone density and its antiosteoporotic values particularly in postmenopausal osteoporosis women.

\section{Oxidative Stress in Postmenopausal Osteoporosis and Antioxidative Role of Tualang Honey}

Bone is continually remodelled throughout life where bone resorption activity by osteoclasts is always followed by bone formation by osteoblasts [37]. Osteoporosis occurs when this bone remodelling cycle is impaired. Hence, any factors that can impair the rate of bone remodelling will contribute to bone loss such as in postmenopausal women where estrogen reduction is the main factor. Estrogen deficiency following menopause can lead to bone loss via direct effects of estrogen on osteoclasts [38] and upregulation of osteoclastogenesis. Upregulation of osteoclastogenesis occurs via activation of receptor activator of nuclear factor kappaB ligand (RANKL) [39] and diminishes production of osteoprotegerin (OPG), which function as osteoclastogenesis inhibitory factor [40]. Postmenopausal osteoporosis can be associated with oxidative stress which results from a disturbance in the balance between free radicals production and antioxidant protective activity. Estrogen can be considered as an antioxidant as it was found to exhibit antioxidant protection of lipoproteins in the aqueous system and was shown to increase the expression of glutathione peroxidase (GPx) in osteoclasts [41]. When body is subjected to high level of oxidative stress following estrogen reduction, lipid accumulation will occur. This will promote osteoblast apoptosis and simultaneously upregulating reactive oxygen 
species (ROS) production, particularly hydrogen peroxide $\left(\mathrm{H}_{2} \mathrm{O}_{2}\right)$ and superoxide anion [42-44]. ROS may increase bone resorption through activation of NF- $\kappa \mathrm{B}$ which plays an important role in osteoclastogenesis. ROS can also promote osteoclast resorption activity directly or by mimicking receptor activator of NF- $\kappa \mathrm{B}$ (RANK) signalling which results in osteoclast differentiation [45]. Some in vitro and animal studies have reported that oxidative stress decreases the level of bone formation by modulating the differentiation and survival of osteoblasts [46, 47]. Postmenopausal women are not only subjected to high level of free radicals and oxidative stress, but in previous studies it was also found that they exhibited higher erythrocyte nitric oxide (NO) levels compared to nonporotic women [48]. NO is able to enhance the ability of cytokines to stimulate osteoclast activity [49] and potentiates the inhibitory effects of those cytokines on osteoblast growth [50,51].

Ovariectomized rat is often used in postmenopausal women research as a model for osteoporosis which exhibits a progressive loss of bone matrix through a process that is similar to what occurs during postmenopausal osteoporosis [52]. This include increased rate of bone turnover with resorption exceeding formation, greater loss of cancellous than cortical bone, and decreased intestinal absorption of calcium [53]. The bone loss following ovariectomy can be due to oxidative stress. In a study by Muthusami et al. (2005), there was a significant decrease in the levels of antioxidant enzymes; superoxide dismutase (SOD), glutathione-stransferases (GST) and GPx in the femur of ovariectomized rats. Hydrogen peroxide and lipid peroxidation were found to increase. These results have shown that oxidative stress was induced in ovariectomized rats which probably is the major factor behind the bone loss in these animals [54]. The ability of cells to scavenge the harmful ROS is mainly dependent upon the efficacy of the antioxidant defense system which comprises of enzymatic antioxidants such as SOD, GPx and catalase (CAT) and nonenzymatic antioxidants such as glutathione $(\mathrm{GSH})$, vitamin $\mathrm{C}$ and $\mathrm{E}[55,56]$. Hence, supplementation with antioxidant is required to combat the oxidative stress and subsequently preventing bone loss. Based on recent published studies, amongst the natural products that are able to prevent osteoporosis are vitamin E tocotrienol and Labisia pumila. Both of these natural products possess antioxidative effects $[57,58]$. According to Nazrun et al. (2011) tocotrienol exert a potent antioxidative property which is able to suppress bone resorbing cytokines and thus preventing osteoporosis.

Over the past few years, a resurgence of interest in the ability of honey as an antioxidant followed by its protective effects on bone has occurred. Tualang honey has been shown to exhibit good antioxidant and antiradical activities $[59,60]$. Study performed by Zaid et al. (2010) has shown that daily consumption of Tualang honey for two weeks in female ovariectomized rats was able to promote an increase in bone density [61]. This positive effect on bone of ovariectomized rats is probably due to the antioxidants found in honey such as flavonoids and phenolic acids [62, 63]. The main phenolic and flavonoid compounds in Tualang honey include kaempferol, quercetin, ellagic acid, gallic acid, hesperetin, and catechin [64].

A study on the antioxidative compounds of Tualang honey has found that Tualang honey had the highest total phenolic and protein content compared to other types of honey; Gelam, Indian forest and Pineapple honey. Among this group of honeys, Tualang honey also had the highest ascorbic acid content which may be responsible for the elevated scavenging of the ROS. In contrast to those types of honey mentioned, Tualang honey had also shown the highest DPPH radical scavenging activity, suggesting that it may contain the most effective free-radical scavenging compounds [60]. These findings have shown that Tualang honey is a good source of antioxidant that is able to scavenge free radicals, resulting in reduced bone resorption activity by osteoclasts which subsequently maintaining the bone health.

Previous studies reported that flavonoids mainly quercetin and kaempferol exert a potent inhibitory effect on osteoclastic bone resorption and apoptosis in a rabbit long bone osteoclast model [65]. They are also involved in inhibition of NF- $\kappa \mathrm{B}$ and activator protein (AP-1), a transcription factor highly related to osteoclastic differentiation [66]. There were some investigations suggesting that quercetin plays an important role in bone loss inhibition by affecting osteoclastogenesis and accelerating TNF- $\alpha$ induced osteoblast growth inhibition and apoptosis [67]. Flavonoids may also inhibit RANKL-induced formation of multinucleated osteoclasts and expression of osteoclastic differentiation markers; RANK and osteocalcin receptor [68]. Flavonoids have been shown to inhibit production of nitric oxide and expression of inducible nitric oxide synthase (iNOS) [69] which will result in inhibition of osteoclast activity. These protective mechanisms of flavonoids on bone strongly indicate that it can be considered as protective agent against bone loss.

\section{Anti-Inflammatory Effects of Tualang Honey}

Osteoporosis is more prevalent in inflammatory conditions such as rheumatoid arthritis, systemic lupus erythematosus (SLE), haematological diseases, inflammatory bowel disease and other inflammatory diseases when compared to the healthy population [70]. Proinflammatory cytokines such as tumor necrosis factor (TNF)- $\alpha$, interleukin (IL)-1, IL-6, IL7, IL-11, IL-15 and IL-17 are elevated in these conditions [71]. Elevation of these cytokines will then result in increase production of prostaglandin $\mathrm{E}_{2}\left(\mathrm{PGE}_{2}\right)$, an inflammatory mediator which consequently stimulates osteoclastic activity [72]. Therefore, osteoporosis can be strongly associated with inflammation. Activated osteoclasts are usually found in the presence of accessory cells including stromal cells, cells in osteoclast lineage and cells involved in the inflammatory responses. These cells posses the ability to express proinflammatory cytokines. Thse proinflammatory cytokines has been shown capable of stimulating osteoclastic bone resorption [73].

There is evidence from previous studies to suggest that postmenopausal bone loss may be linked to activation of osteoclasts by proinflammatory cytokines [74-76]. Estrogen 


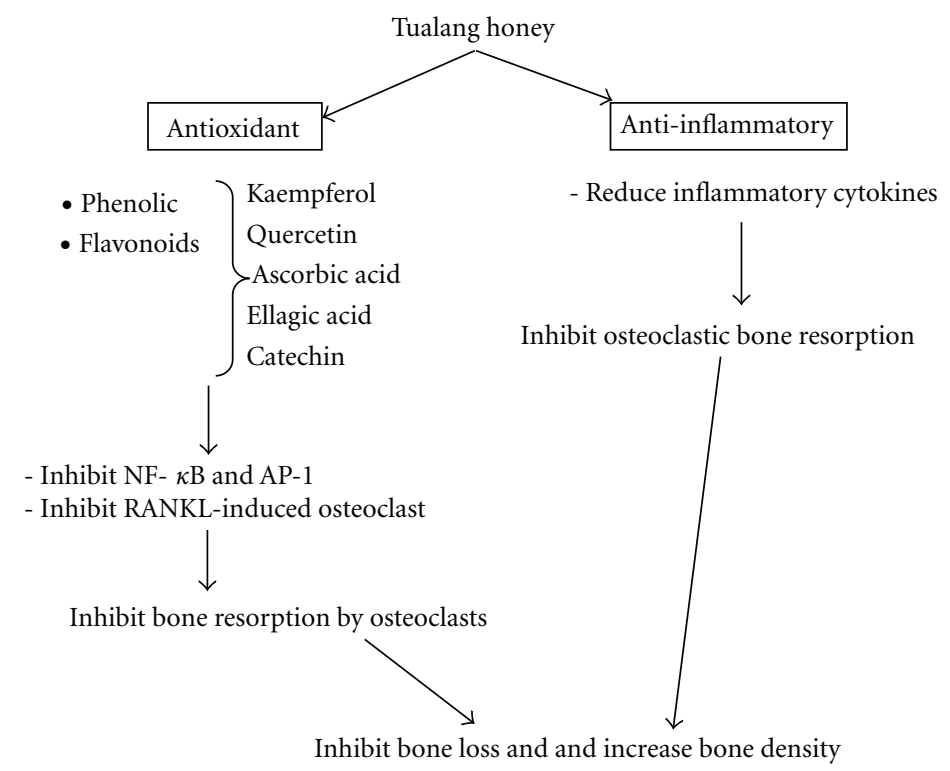

FIGURE 1: Schematic diagram of antioxidative and anti-inflammatory actions of Tualang honey on bone.

is able to suppress production of these cytokines and stimulate production of OPG $[77,78]$. Thus, estrogen withdrawal following menopause will result in an increase in these cytokines and simultaneously lead to downregulation of OPG, resulting in local inflammation in the bone. Ovariectomy in rats was accompanied by an increase in production of TNF- $\alpha$ and IL-1 [79]. This may influence osteoclastogenesis by stimulating self-renewal and inhibiting the apoptosis of osteoclast progenitors [80]. They also support osteoclast formation and activation mediated by RANKL and macrophage colony-stimulating factor (M-CSF). These studies have shown that postmenopausal osteoporosis can be associated with inflammation.

Honey does not only exhibit antioxidative effects but it also possesses anti-inflammatory effects. Previous studies have shown that the level of $\mathrm{PGE}_{2}$ was reduced after the ingestion of honey [81]. Recent study has also shown that honey was able to exert anti-inflammatory effect via inhibition of nitric oxide [82]. Consumption of Tualang honey for two weeks in female ovariectomized rats was able to increase bone density. Tibial bones of the ovariectomized rats treated with Tualang honey were comparable to those of control nonovariectomized rats [61]. This result can strongly suggests that Tualang honey was able to restore osteoporotic bone similar to the nonosteoporotic bone.

Another study performed on the effects of Tualang honey on postmenopausal women showed that daily intake of Tualang honey at $20 \mathrm{mg} /$ day for four months was found to be safe and exerted the same effect on bone densitometry when compared to hormone replacement therapy [83]. Based on this result, it was shown that Tualang honey was able to produce an effective result as HRT and can be used as anti-osteoporotic agent. These positive effects of Tualang honey on bone are probably due to its anti-inflammatory property, apart from the antioxidative property mentioned. Other than that, it was found out that its anti-osteoporotic property could probably due to the presence of calcium [84] and gluconic acid. Gluconic acid could enhance calcium absorption in the bone which consequently maintaining bone mass and prevent osteoporosis [85]. These results proved that Tualang honey has the potential to be used as an alternative treatment in treating postmenopausal osteoporosis. The antioxidative and anti-inflammatory actions of Tualang honey are summarized in Figure 1.

From nutrition point of view, Tualang honey is a sugar. For sweeteners, a maximum of 40 to $50 \mathrm{~g}$ per day is generally accepted. However, the recommended dose is about $20 \mathrm{~g}$ daily [86]. This is the reason why majority of the researches were done with the dose of $20 \mathrm{~g}$ daily such seen in study of the effects of Tualang honey on postmenopausal women [83]. A previous study on the hepatoprotective effect of Tualang honey supplementation in streptozotocin-induced diabetic rat has shown that diabetic rats supplemented with Tualang honey had a reduced blood glucose concentration compared to the control diabetic rats group [87]. This result suggests that Tualang honey is safe to be consumed by postmenopausal diabetic women. Since Tualang honey is a food supplement, not many studies have been done on its drug interaction. Previous study has provided evidence for the in vitro inhibition of cytochrome P450 2C8 (CYP2C8) activity by Tualang honey. It revealed that this honey, through this inhibition, may have the potential to cause in vivo drug-food interaction with drugs metabolized by CYP2C8 [35] such as thiazolidinediones, a class of antidiabetic drug and amodiaquine, an antimalarial agent [88]. More clinical studies should be performed in order to study the safety of Tualang honey on diabetic patients and its interaction with other drug hence, providing a more accurate proof of its safety profile.

Based on the positive effects on bone density, Tualang honey has the potential to be used as an alternative treatment for postmenopausal osteoporosis due to its anti-oxidative 
and anti-inflammatory properties against bone loss. As Tualang honey was able to produce results as effective as HRT, it can be used as an alternative in order to prevent bone loss with minimal side effects. However, there are few studies performed to observe the effects of Tualang honey on bone metabolism. More studies and clinical trials are required to explore the mechanism of Tualang honey on overall bone metabolism and its side effects.

\section{Acknowledgment}

The author would like to thank the University Kebangsaan Malaysia (UKM) for the grants and the Pharmacology Department staff for their technical support.

\section{References}

[1] WHO, Traditional Medicine, WHO, Geneva, Switzerland, 2003.

[2] WHO, Traditional Medicine, WHO Congress, Beijing, China, 2008.

[3] J. H. Thrall, "Prevalence and costs of chronic disease in a health care system structured for treatment of acute illness," Radiology, vol. 235, no. 1, pp. 9-12, 2005.

[4] C. Christiansen, "Consensus Development Conference: prophylaxis and treatment of osteoporosis," American Journal of Medicine, vol. 90, no. 1, pp. 107-110, 1991.

[5] National Osteoporosis Foundation Prevalence Report, Washington, DC, USA, 2010.

[6] J. P. Bilezikian, "Osteoporosis in men," Journal of Clinical Endocrinology and Metabolism, vol. 84, no. 10, pp. 3431-3434, 1999.

[7] E. Gielen, D. Vanderschueren, F. Callewaert, and S. Boonen, "Osteoporosis in men," Best Practice and Research, vol. 25, no. 2, pp. 321-335, 2011.

[8] S. Lauralee, Fundamentals of Physiology: A Human Perspective, Brooks/Coe Cengage Learning, Ontario, Canada, 4th edition, 2011.

[9] F. Callewaert, S. Boonen, and D. Vanderschueren, "Sex steroids and the male skeleton: a tale of two hormones," Trends in Endocrinology and Metabolism, vol. 21, no. 2, pp. 89-95, 2010.

[10] E. Legrand, C. Hedde, Y. Gallois et al., "Osteoporosis in men: a potential role for the sex hormone binding globulin," Bone, vol. 29, no. 1, pp. 90-95, 2001.

[11] N. F. Ray, J. K. Chan, M. Thamer, and L. J. Melton III, "Medical expenditures for the treatment of osteoporotic fractures in the United States in 1995: report from the National Osteoporosis Foundation," Journal of Bone and Mineral Research, vol. 12, no. 1, pp. 24-35, 1997.

[12] E. S. Orwoll, "Osteoporosis in men," Endocrinology and Metabolism Clinics of North America, vol. 27, no. 2, pp. 349367, 1998.

[13] V. Gilsanz, "Accumulation of bone mass during childhood and adolescence," in Osteoporosis in Men, E. S. Orwoll, Ed., pp. 6568, Academic Press, San Diego, Calif, USA, 2nd edition, 1999.

[14] A. R. Rodney and R. B. David, Medical Physiology: Principles for Clinical Medicine, Lippincott Williams \& Wilkins, Philadelphia, Pa, USA, 4th edition, 2001.

[15] S. Boonen, J. J. Body, Y. Boutsen et al., "Evidence-based guidelines for the treatment of postmenopausal osteoporosis: a consensus document of the Belgian Bone Club," Osteoporosis International, vol. 16, no. 3, pp. 239-254, 2005.
[16] D. J. Torgerson and S. E. M. Bell-Syer, "Hormone replacement therapy and prevention of nonvertebral fractures: a metaanalysis of randomized trials," Journal of the American Medical Association, vol. 285, no. 22, pp. 2891-2897, 2001.

[17] C. Schairer, J. Lubin, R. Troisi, S. Sturgeon, L. Brinton, and R. Hoover, "Menopausal estrogen and estrogen-progestin replacement therapy and breast cancer risk," Journal of the American Medical Association, vol. 283, no. 4, pp. 485-491, 2000.

[18] R. J. Santen, J. Pinkerton, C. McCartney, and G. R. Petroni, "Clinical review 121: risk of breast cancer with progestins in combination with estrogen as hormone replacement therapy," Journal of Clinical Endocrinology and Metabolism, vol. 86, no. 1, pp. 16-23, 2001.

[19] Collaborative Group on Hormonal Factors for Breast Cancer, "Breast cancer and hormone replacement therapy: collaborative reanalysis of data from 51 epidemiological studies of 52,705 women with breast cancer and 108,411 women without breast cancer," The Lancet, vol. 350, no. 9084, pp. 1047-1059, 1997.

[20] B. Reiner, F. Bertha, V. T. Emmo, and B. Christoph, Biphosphonates in Medical Practice, Springer, New York, USA, 2007.

[21] R. Makins and A. Ballinger, "Gastrointestinal side effects of drugs," Expert Opinion on Drug Safety, vol. 2, no. 4, pp. 421429, 2003.

[22] S. Khosla, D. Burr, J. Cauley et al., "Bisphosphonate-associated osteonecrosis of the jaw: report of a Task Force of the American Society for Bone and Mineral Research," Journal of Bone and Mineral Research, vol. 22, no. 10, pp. 1479-1491, 2007.

[23] P. C. Molan, "Why honey is effective as a medicine. I. Its use in modern medicine," Bee World, vol. 80, no. 2, pp. 80-92, 1999.

[24] E. Crane, "History of honey," in Honey, A Comprehensive Survey, E. Crane, Ed., pp. 439-388, William Heiemann, London, UK, 1975.

[25] R. Jones, "Honey and healing through ages," in Honey and Healing, P. Munn and R. Jones, Eds., pp. 1-4, Cardiff: International Bee Research Association IBRA, 2001.

[26] A. J. Van den Berg, E. van den Worm, H. C. Van Ufford, S. B. Halkes, M. J. Hoekstra, and C. J. Beukelman, "An in vitro examination of the antioxidant and anti-inflammatory properties of buckwheat honey," Journal of Wound Care, vol. 17, no. 4, pp. 172-178, 2008.

[27] P. C. Molan, "The evidence supporting the use of honey as a wound dressing," International Journal of Lower Extremity Wounds, vol. 5, no. 1, pp. 40-54, 2006.

[28] O. O. Erejuwa, S. Gurtu, S. A. Sulaiman, M. S. A. Wahab, K. N. S. Sirajudeen, and M. S. Salleh, "Hypoglycemic and antioxidant effects of honey supplementation in streptozotocininduced diabetic rats," International Journal for Vitamin and Nutrition Research, vol. 80, no. 1, pp. 74-82, 2010.

[29] M. Kassim, M. Achoui, M. R. Mustafa, M. A. Mohd, and K. M. Yusoff, "Ellagic acid, phenolic acids, and flavonoids in Malaysian honey extracts demonstrate in vitro anti-inflammatory activity," Nutrition Research, vol. 30, no. 9, pp. 650-659, 2010.

[30] O. O. Erejuwa, S. A. Sulaiman, and M. S. Wahab, "Fructose might contribute to the hypoglycaemic effect of honey," Molecules, vol. 17, no. 2, pp. 1900-1915, 2012.

[31] S. Bogdanov, T. Jurendic, R. Sieber, and P. Gallmann, "Honey for nutrition and health: a review," Journal of the American College of Nutrition, vol. 27, no. 6, pp. 677-689, 2008. 
[32] M. Al-Mamary, A. Al-Meeri, and M. Al-Habori, "Antioxidant activities and total phenolics of different types of honey," Nutrition Research, vol. 22, no. 9, pp. 1041-1047, 2002.

[33] A. R. Pérez, M. T. Iglesias, E. Pueyo, M. González, and C. de Lorenzo, "Amino acid composition and antioxidant capacity of Spanish honeys," Journal of Agricultural and Food Chemistry, vol. 55, no. 2, pp. 360-365, 2007.

[34] A. Z. Mat Saad, W. S. Wan Azman, S. H. Ahmad, Y. S. Mohd, and H. Jaafar, "The efficacy of Tualang honey in comparison to silver dressing wounds in rats," Journal of ApiProduct and ApiMedical Science, vol. 3, no. 1, pp. 45-53, 2011.

[35] D. M. Yasotha, E. O. Chin, A. S. Siti, C. T. Soo, and I. Rusli, "In vitro inhibitory effect of Tualang honey oncytochrome P450 2C8 activity," Journal of Pharmacy and Pharmacology, pp. 1-9, 2012.

[36] G. Beretta, M. Orioli, and R. M. Facino, "Antioxidant and radical scavenging activity of honey in endothelial cell cultures (EA.hy926)," Planta Medica, vol. 73, no. 11, pp. 1182-1189, 2007.

[37] P. A. Hill, "Bone remodelling," British Journal of Orthodontics, vol. 25, no. 2, pp. 101-107, 1998.

[38] S. Srivastava, G. Toraldo, M. N. Weitzmann, S. Cenci, F. P. Ross, and R. Pacifici, "Estrogen decreases osteoclast formation by down-regulating receptor activator of NF- $\kappa$ B ligand (RANKL)-induced JNK activation," Journal of Biological Chemistry, vol. 276, no. 12, pp. 8836-8840, 2001.

[39] G. Eghbali-Fatourechi, S. Khosla, A. Sanyal, W. J. Boyle, D. L. Lacey, and B. L. Riggs, "Role of RANK ligand in mediating increased bone resorption in early postmenopausal women," Journal of Clinical Investigation, vol. 111, no. 8, pp. 1221-1230, 2003.

[40] L. C. Hofbauer, S. Khosla, C. R. Dunstan, D. L. Lacey, T. C. Spelsberg, and B. L. Riggs, "Estrogen stimulates gene expression and protein production of osteoprotegerin in human osteoblastic cells," Endocrinology, vol. 140, no. 9, pp. 4367-4370, 1999.

[41] M. Badeau, H. Adlercreutz, P. Kaihovaara, and M. J. Tikkanen, "Estrogen A-ring structure and antioxidative effect on lipoproteins," Journal of Steroid Biochemistry and Molecular Biology, vol. 96, no. 3-4, pp. 271-278, 2005.

[42] E. Amir, O. C. Freedman, B. Seruga, and D. G. Evans, "Assessing women at high risk of breast cancer: a review of risk assessment models," Journal of the National Cancer Institute, vol. 102, no. 10, pp. 680-691, 2010.

[43] D. Maggio, M. Barabani, M. Pierandrei et al., "Marked decrease in plasma antioxidants in aged osteoporotic women: results of a cross-sectional study," Journal of Clinical Endocrinology and Metabolism, vol. 88, no. 4, pp. 1523-1527, 2003.

[44] M. Almeida, L. Han, M. Martin-Millan et al., "Skeletal involution by age-associated oxidative stress and its acceleration by loss of sex steroids," Journal of Biological Chemistry, vol. 282, no. 37, pp. 27285-27297, 2007.

[45] W. Fabien, L. Laurent, C. Veronique, G. Jerome, and W. Yohann, "Oxidative stress in bone remodelling and disease," Trends in Molecular Medicine, vol. 15, no. 10, pp. 468-477, 2009.

[46] N. Mody, F. Parhami, T. A. Sarafian, and L. L. Demer, "Oxidative stress modulates osteoblastic differentiation of vascular and bone cells," Free Radical Biology and Medicine, vol. 31, no. 4, pp. 509-519, 2001.

[47] X. C. Bai, D. Lu, J. Bai et al., "Oxidative stress inhibits osteoblastic differentiation of bone cells by ERK and NF- $\kappa \mathrm{B}$,"
Biochemical and Biophysical Research Communications, vol. 314, no. 1, pp. 197-207, 2004.

[48] O. Salih, K. Huseyin, F. Ersin, A. Rabia, and Y. Zumrut, "Role of antioxidant systems, lipid peroxidation, and nitric oxide in postmenopausal osteoporosis," Molecular and Cellular Biochemistry, vol. 295, no. 1-2, pp. 45-52, 2007.

[49] R. J. Van'T Hof and S. H. Ralston, "Cytokine-induced nitric oxide inhibits bone resorption by inducing apoptosis of osteoclast progenitors and suppressing osteoclast activity," Journal of Bone and Mineral Research, vol. 12, no. 11, pp. 17971804, 1997.

[50] S. H. Ralston, D. Todd, M. Helfrich, N. Benjamin, and P. S. Grabowski, "Human osteoblast-like cells produce nitric oxide and express inducible nitric oxide synthase," Endocrinology, vol. 135, no. 1, pp. 330-336, 1994.

[51] H. MacPherson and S. H. Ralston, "Expression and functional role of nitric oxide synthase isoforms in human osteoblast-like cells," Bone, vol. 24, no. 3, pp. 179-185, 1999.

[52] P. Ammann, R. Rizzoli, D. Slosman, and J. P. Bonjour, "Sequential and precise in vivo measurement of bone mineral density in rats using dual-energy x-ray absorptiometry," Journal of Bone and Mineral Research, vol. 7, no. 3, pp. 311316, 1992.

[53] D. N. Kalu, "The ovariectomized rat model of postmenopausal bone loss," Bone and Mineral, vol. 15, no. 3, pp. 175-191, 1991.

[54] S. Muthusami, I. Ramachandran, B. Muthusamy et al., "Ovariectomy induces oxidative stress and impairs bone antioxidant system in adult rats," Clinica Chimica Acta, vol. 360, no. 1-2, pp. 81-86, 2005.

[55] B. Halliwell and J. M. C. Gutteridge, Free Radicals in Biology and Medicine, Clarendon Press, Oxford, UK, 2007.

[56] B. Halliwell, "Free radicals and antioxidants-quo vadis?" Trends in Pharmacological Sciences, vol. 32, no. 3, pp. 125-130, 2011.

[57] A. S. Nazrun, M. Norazlina, M. Norliza, and S. I. Nirwana, "The anti-inflammatory role of vitamin $\mathrm{E}$ in prevention of osteoporosis," Advance in Pharmacological Sciences, vol. 2012, Article ID 142702, pp. 1-7, 2012.

[58] M. E. Nadia, A. S. Nazrun, M. Norazlina, N. M. Isa, M. Norliza, and S. Ima Nirwana, "The anti-inflammatory, phytoestrogenic and antioxidative role of Labisia pumila in prevention of postmenopausal osteoporosis," Advances in Pharmacological Sciences, vol. 2012, Article ID 706905, 7 pages, 2012.

[59] M. Mohamed, K. N. S. Sirajudeen, M. Swamy, N. S. Yaacob, and S. A. Sulaiman, "Studies on the antioxidant properties of tualang honey of Malaysia," African Journal of Traditional, Complementary and Alternative Medicines, vol. 7, no. 1, pp. 5963, 2010.

[60] R. K. Kishore, A. S. Halim, M. S. N. Syazana, and K. N. S. Sirajudeen, "Tualang honey has higher phenolic content and greater radical scavenging activity compared with other honey sources," Nutrition Research, vol. 31, no. 4, pp. 322-325, 2011.

[61] S. S. M. Zaid, S. A. Sulaiman, K. N. M. Sirajudeen, and N. H. Othman, "The effects of tualang honey on female reproductive organs, tibia bone and hormonal profile in ovariectomised rats-animal model for menopause," BMC Complementary and Alternative Medicine, vol. 10, article 82, 2010.

[62] S. K. Jaganathan and M. Mandal, "Antiproliferative effects of honey and of its polyphenols: a review," Journal of Biomedicine and Biotechnology, vol. 2009, Article ID 830616, 13 pages, 2009.

[63] S. Buratti, S. Benedetti, and M. S. Cosio, "Evaluation of the antioxidant power of honey, propolis and royal jelly by 
amperometric flow injection analysis," Talanta, vol. 71, no. 3, pp. 1387-1392, 2007.

[64] S. Z. Hussein, K. M. Yusoff, S. Makpol, and Y. A. Yusof, "Antioxidant capacities and total phenolic contents increase with gamma irradiation in two types of Malaysian honey," Molecules, vol. 16, no. 8, pp. 6378-6395, 2011.

[65] A. Wattel, S. Kamel, R. Mentaverri et al., "Potent inhibitory effect of naturally occurring flavonoids quercetin and kaempferol on in vitro osteoclastic bone resorption," Biochemical Pharmacology, vol. 65, no. 1, pp. 35-42, 2003.

[66] A. Wattel, S. Kamel, C. Prouillet et al., "Flavonoid quercetin decreases osteoclastic differentiation induced by RANKL via a mechanism involving $\mathrm{NF} \kappa \mathrm{B}$ and AP-1," Journal of Cellular Biochemistry, vol. 92, no. 2, pp. 285-295, 2004.

[67] Y. O. Son, S. H. Kook, K. C. Choi et al., "Quercetin, a bioflavonoid, accelerates TNF- $\alpha$-induced growth inhibition and apoptosis in MC3T3-E1 osteoblastic cells," European Journal of Pharmacology, vol. 529, no. 1-3, pp. 24-32, 2006.

[68] J. L. Pang, D. A. Ricupero, S. Huang et al., "Differential activity of kaempferol and quercetin in attenuating tumor necrosis factor receptor family signaling in bone cells," Biochemical Pharmacology, vol. 71, no. 6, pp. 818-826, 2006.

[69] J. González-Gallego, S. Sánchez-Campos, and M. J. Tuñón, "Anti-inflammatory properties of dietary flavonoids," Nutricion Hospitalaria, vol. 22, no. 3, pp. 287-293, 2007.

[70] G. R. Mundy, "Osteoporosis and inflammation," Nutrition Reviews, vol. 65, no. 12, pp. S147-151, 2007.

[71] K. Ishihara and T. Hirano, "IL-6 in autoimmune disease and chronic inflammatory proliferative disease," Cytokine and Growth Factor Reviews, vol. 13, no. 4-5, pp. 357-368, 2002.

[72] J. H. Francis, D. K. Lee, V.J.H Mik, A. O’Donnell, M. Jacques, and M. P. Julia, "Cytokine-induced prostaglandin $\mathrm{E}_{2}$ synthesis and cyclooxygenase- 2 activity are regulated both by a nitric oxide-dependent and -independent mechanism in rat osteoblasts in vitro," Journal of Biological Chemistry, vol. 274, no. 3, pp. 1776-1782, 1999.

[73] S. V. Reddy and G. D. Roodman, "Control of osteoclast differentiation," Critical Reviews in Eukaryotic Gene Expression, vol. 8, no. 1, pp. 1-17, 1998.

[74] R. Pacifici, C. Brown, E. Puscheck et al., "Effect of surgical menopause and estrogen replacement on cytokine release from human blood mononuclear cells," Proceedings of the National Academy of Sciences of the United States of America, vol. 88, no. 12, pp. 5134-5138, 1991.

[75] G. R. Mundy, “Osteoporosis and inflammation," Nutrition Reviews, vol. 65, no. 12, pp. S147-151, 2007.

[76] Y. Ishimi, C. Miyaura, C. H. Jin et al., "IL-6 is produced by osteoblasts and induces bone resorption," The Journal of Immunology, vol. 145, no. 10, pp. 3297-3303, 1990.

[77] R. L. Jilka, "Cytokines, bone remodeling, and estrogen deficiency: a 1998 update," Bone, vol. 23, no. 2, pp. 75-81, 1998.

[78] L. C. Hofbauer, S. Khosla, C. R. Dunstan, D. L. Lacey, T. C. Spelsberg, and B. L. Riggs, "Estrogen stimulates gene expression and protein production of osteoprotegerin in human osteoblastic cells," Endocrinology, vol. 140, no. 9, pp. 4367-4370, 1999.

[79] R. B. Kimble, A. B. Matayoshi, J. L. Vannice, V. T. Kung, C. Williams, and R. Pacifici, "Simultaneous block of interleukin1 and tumor necrosis factor is required to completely prevent bone loss in the early postovariectomy period," Endocrinology, vol. 136, no. 7, pp. 3054-3061, 1995.
[80] G. Girasole, G. Passeri, R. L. Jilka, and S. C. Manolagas, "Interleukin-11: a new cytokine critical for osteoclast development," Journal of Clinical Investigation, vol. 93, no. 4, pp. 1516-1524, 1994.

[81] N. S. Al-Waili and N. S. Boni, "Natural honey lowers plasma prostaglandin concentrations in normal individuals," Journal of Medicinal Food, vol. 6, no. 2, pp. 129-133, 2003.

[82] B. V. Owoyele, O. T. Adenekan, and A. O. Soladoye, "Effects of honey on inflammation and nitric oxide production in Wistar rats," Journal of Chinese Integrative Medicine, vol. 9, no. 4, pp. 447-452, 2011.

[83] H. Lily, N. H. Nik Hazlina, S. Siti Amrah et al., "The effects of Tualang honey on postmenopausal women," in Proceedings of the 2nd International Conference on the Medicinal Use of Honey, vol. 2 of Journal of ApiProduct and ApiMedical Science, no. 1, pp. 31-60, Kota Bharu, Malaysia, 2010.

[84] C. G. Farid, "Morphological characterization study of Malaysian honey - a VPSEM, EDX Randomised attempt," Annals of Microscopy, vol. 9, pp. 93-100, 2009.

[85] M. W. Ariefdjohan, B. R. Martin, P. J. Lachcik, and C. M. Weaver, "Acute and chronic effects of honey and its carbohydrate constituents on calcium absorption in rats," Journal of Agricultural and Food Chemistry, vol. 56, no. 8, pp. 2649-2654, 2008.

[86] S. Bogdanov, T. Jurendic, R. Sieber, and P. Gallmann, "Honey for nutrition and health: a review," Journal of the American College of Nutrition, vol. 27, no. 6, pp. 677-689, 2008.

[87] O. O. Erejuwa, S. A. Sulaiman, M. S. Wahab, K. N. S. Sirajudeen, M. S. Salleh, and S. Gurtu, "Hepatoprotective effect of Tualang honey supplementation in streptozotocin-induced diaibetic rats," International Journal of Applied Research in Natural Products, vol. 4, no. 4, pp. 37-41, 2012.

[88] F. H. Paul and S. Joann, Drug Metabolism Handbook: Concepts and Applications, John Wiley \& Sons, New Jersey, NJ, USA, 2009. 


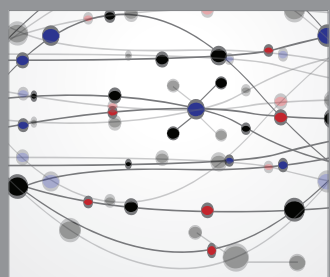

The Scientific World Journal
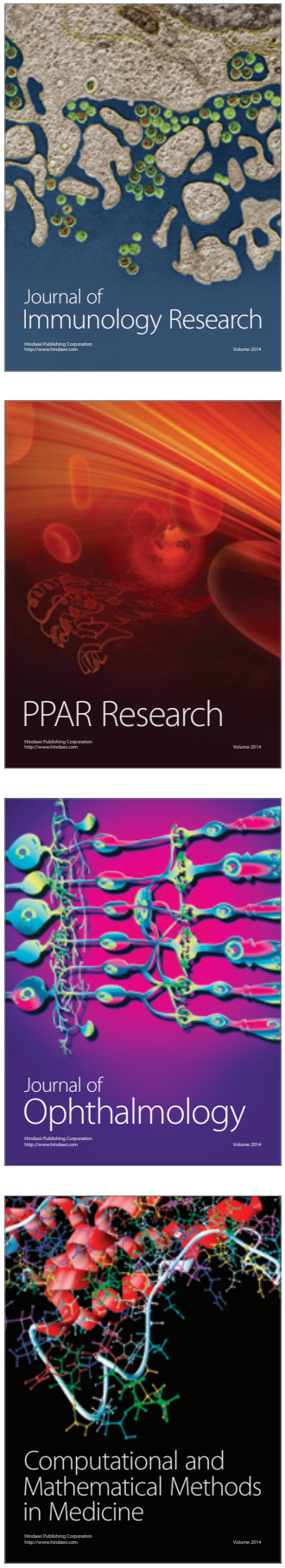

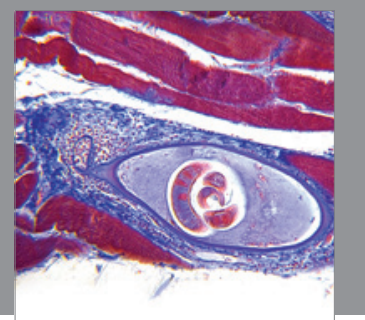

Gastroenterology

Research and Practice
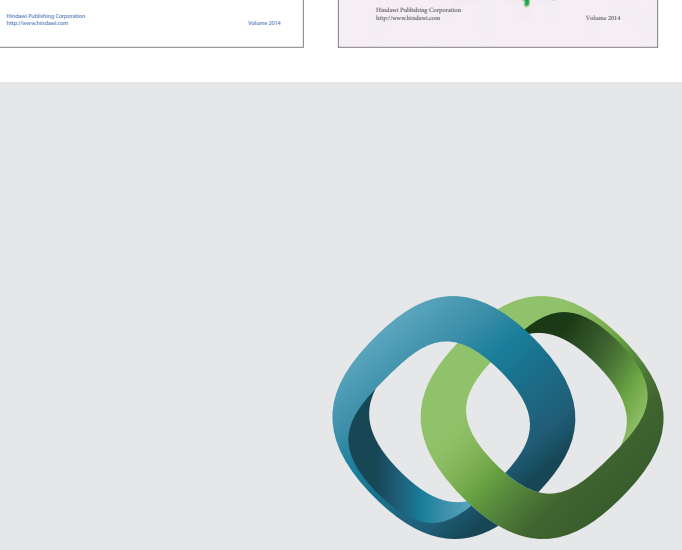

\section{Hindawi}

Submit your manuscripts at

http://www.hindawi.com
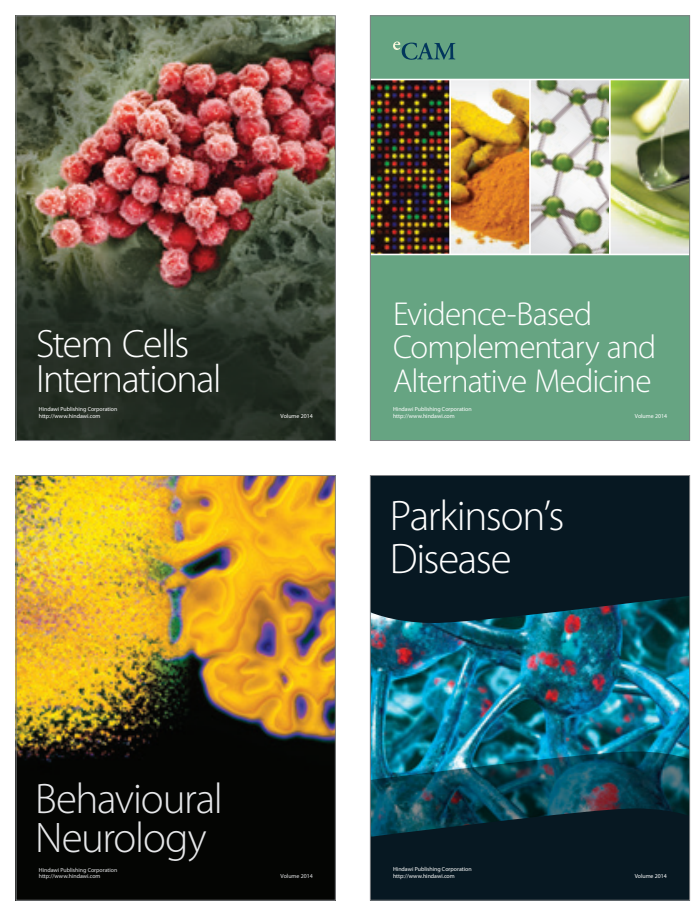

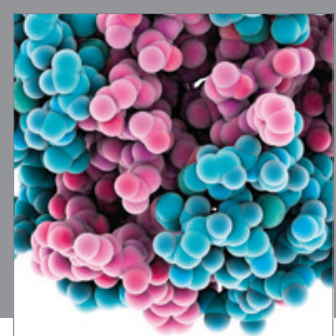

Journal of
Diabetes Research

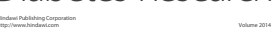

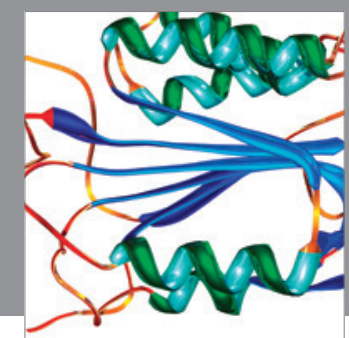

Disease Markers
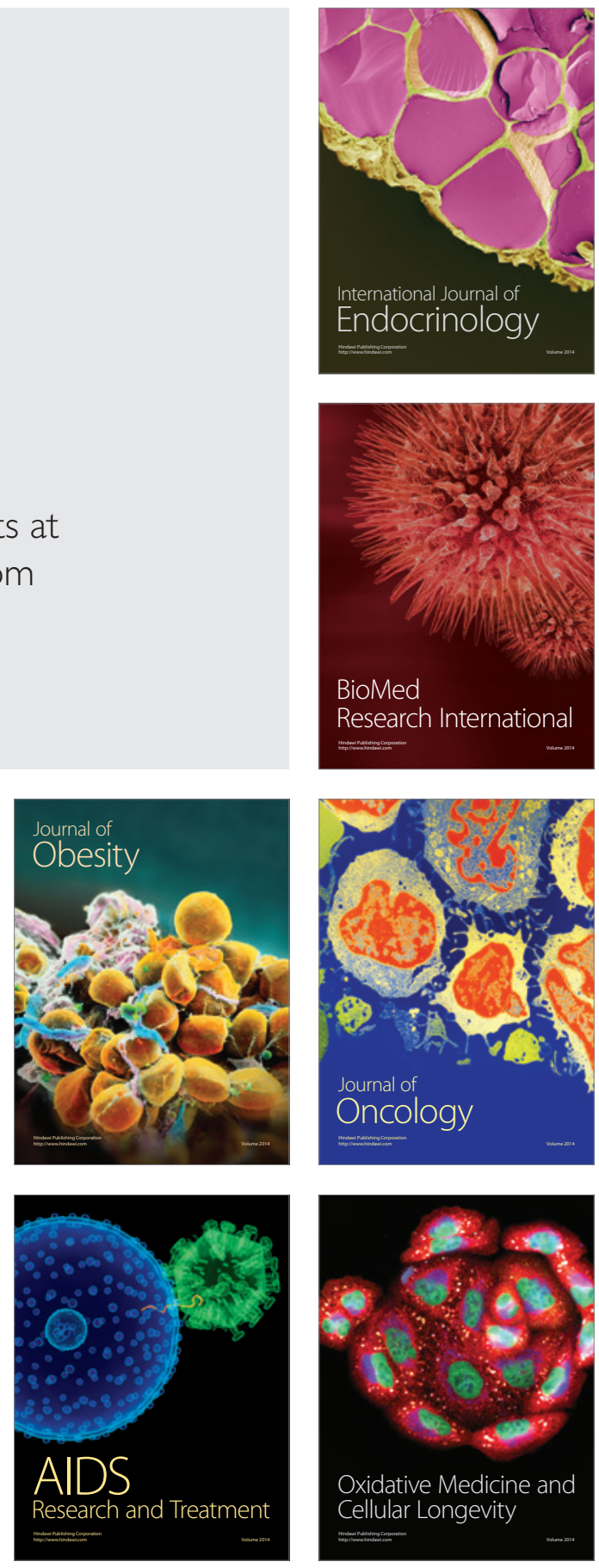